Research Article

\title{
Simplified Data-Driven Model for the Moment Curvature of T-Shaped RC Shear Walls
}

\author{
Bin Wang $\mathbb{D}^{1,2}$ Wenzhe Cai $\mathbb{D}^{1},{ }^{1}$ and Qingxuan Shi $\mathbb{D}^{1,2}$ \\ ${ }^{1}$ State Key Laboratory of Green Building in Western China, Xi'an University of Architecture and Technology, Xi'an 710055, China \\ ${ }^{2}$ School of Civil Engineering, Xi'an University of Architecture and Technology, Xi'an 710055, China \\ Correspondence should be addressed to Bin Wang; wangbin@xauat.edu.cn
}

Received 8 May 2019; Revised 14 September 2019; Accepted 11 October 2019; Published 3 November 2019

Academic Editor: Flavio Stochino

Copyright (c) 2019 Bin Wang et al. This is an open access article distributed under the Creative Commons Attribution License, which permits unrestricted use, distribution, and reproduction in any medium, provided the original work is properly cited.

Sectional deformation quantities, such as curvature and ductility, are of prime significance in the displacement-based seismic design and performance evaluation of structural members. However, few studies on the estimates of curvatures at different limit states have been performed on asymmetric flanged walls. In this paper, a parametric study was performed for a series of T-shaped wall cross-sections based on moment-curvature analyses. By investigating the effects of the axial load ratio, reinforcement content, material properties, and geometric parameters on curvatures at the yield and ultimate limit state, we interpret the variation in curvature with different influencing factors in detail according to the changes of the neutral axis depth. Based on the regression analyses of the numerical results of $4941 \mathrm{~T}$-shaped cross-sections, simple expressions to estimate the yield curvature and ultimate curvature for asymmetric flanged walls are developed, and simplified estimates of the ductility capacity including curvature ductility and displacement ductility are further deduced. By comparing with the experimental results, we verify the accuracy of the proposed formulas. Such simple expressions will be valuable for the determination of the displacement response of asymmetric flanged reinforced concrete walls.

\section{Introduction}

In the conventional force-based design, stiffness is assumed to be a fundamental property of the section. Thus, the yield curvature of a section is directly proportional to the yield moment for a given structural member type and size [1]. However, extensive experimental studies on structural members indicate that when the section strength varies with the axial load ratio or flexural reinforcement ratio, the stiffness actually varies approximately in proportion to the strength. Thus, when the section strength is adjusted to satisfy the seismic design requirements, the changes in section stiffness and difficulties in determining the effective stiffness of the structural members will affect the accuracies in the estimates of the natural period of the structure and further cause errors in the distribution of forces to different structural members. Therefore, it is difficult to ensure that the structure designed by the force-based design approach can achieve the predetermined performance goals under different earthquake hazard levels. In contrast, yield curvature is a relatively stable index for a given section size and material properties. Based on the estimate of yield displacement calculated from yield curvature, a displacementbased design approach can produce structural members with adequate ductility. In addition, the ultimate displacement derived from the ultimate curvature and the displacement ductility derived from the curvature ductility are important to evaluate the seismic performance of a structure or structural members.

Studies on the sectional deformation quantities such as the curvature and ductility have mainly concerned on rectangular walls. For the estimates of curvatures at the yield and ultimate limit state, two main methods can be classified based on previous studies. One of them is the "numerical method" [2-6]. Through parametric studies on a series of wall cross-sections based on moment-curvature analyses, the effects of the axial load ratio, reinforcement ratio, and concrete and reinforcing steel strengths on the curvatures 
were quantified; then, empirical formulas to estimate the yield curvature and ultimate curvature were established by regression analyses. However, this method strongly depends on the selected parameters, and the derived formulas are only valid for the range of parameters considered. The other main classification is the "analytical method" [7-10]. By solving the force-equilibrium equation of the cross-section at the yield and ultimate limit state, formulas to determine the neutral axis positions at different limit states were deduced. Then, the formulas to estimate the yield curvature and ultimate curvature were established based on the assumption that the plane sections remained planar. However, such method requires high computational effort. Although Monti and Petrone [11] simplified the calculations in curvatures with closed-form equations, a higher computational cost was required compared to the formulas derived from the "numerical method." In addition, the "analytical method" can only achieve the true yield curvature (first yielding of the longitudinal reinforcement) instead of the effective yield curvature, which is of interest for design purpose. Therefore, the "numerical method" based on plenty sectional analyses with a wide range of different parameters is a relatively reliable method.

For both structural and architectural purposes, linear rectangular shear walls are often connected to form T- or L-shaped flanged walls. The cyclic tests of T-shaped and L-shaped walls completed by the author [12] show that the bearing capacity, stiffness, and ductility of asymmetric flanged walls strongly depend on the loading direction and significantly differ from those of rectangular walls. In particular, a larger deformation capacity can be achieved for the case with the flange in compression, while brittle behaviour and higher stiffness are observed for the case with the flange in tension. Therefore, it is essential to identify the difference in sectional deformation quantities of asymmetric flanged walls in different loading directions before the section design. However, few studies have been conducted. Only Smyrou et al. [1] developed the curvature relationships for the yield, serviceability, and ultimate curvatures for T-shaped walls regarding their asymmetric properties, and the results were graphically and analytically presented as a function of the compressive axial load ratio and reinforcement content. But limited influence factors were considered in this study, so the proposed formulas could only be accurate for the range of parameters considered.

Given the deficient study on the sectional deformation quantities of asymmetric flanged shear walls and the significance of the ductility capacity in the determination of the displacement response, simple expressions must be developed to estimate the curvatures at different limit states. In this paper, a parametric analysis was performed for a series of T-shaped wall cross-sections based on moment-curvature analyses. The effects of the axial load ratio, reinforcement content, material properties, and geometric parameters on the yield curvature and ultimate curvature were investigated in different loading directions (flange in tension and flange in compression). Through regression analyses of extensive numerical results, simplified formulas to estimate the yield curvature, ultimate curvature, and ductility capacity were established.

\section{Moment-Curvature Analyses}

2.1. Modeling Approach. Moment-curvature analyses were conducted using XTRACT, which is a fiber-based finite element software for the nonlinear analysis of cross-sections of reinforced concrete members, formerly known as UCFyber. In XTRACT, the entire moment-curvature response is calculated by an incremental analysis that satisfies the strain compatibility, material stress-strain relationships, and equilibrium. Specifically, for a given curvature and neutral axis, the strain of each element is calculated using the assumption of linear strain distribution. Then, the stress of each element and the resultant force of the cross-section are calculated from the stress-strain relationship of the confined or unconfined concrete. Iterative calculations are performed until the force equilibrium in the cross-section is satisfied [7]. This process is repeated with increasing the curvature incrementally until the curvature reaches the maximum allowable value.

Figure 1(a) shows the prototype walls tested by the author used for numerical analysis. The wall is $100 \mathrm{~mm}$ thick with a web length of $1000 \mathrm{~mm}$ and a flange length of $900 \mathrm{~mm}$. More detailed experimental information is available elsewhere [12]. For numerical analysis, the wall crosssection is discretized into small fiber elements, as shown in Figure 1(b).

The nonlinear behaviour of concrete and reinforcing bars can be simulated using the built-in material models of XTRACT. The model proposed by Mander et al. [13] was used to define the concrete behaviour. Figure 2 shows the stress-strain relations of the confined and unconfined concrete used for numerical analysis, where $\varepsilon_{\mathrm{c}}$ and $\sigma_{\mathrm{c}}$ are the concrete strain and stress, respectively, $\varepsilon_{\mathrm{c} 0}$ and $\varepsilon_{\mathrm{cc}}$ are the peak compressive strains of unconfined and confined concrete, respectively, $\varepsilon_{\mathrm{cu}}$ and $\varepsilon_{\mathrm{ccu}}$ are the ultimate compressive strains of unconfined and confined concrete, respectively, $f_{\mathrm{c} 0}$ and $f_{\mathrm{cc}}$ are the peak compressive stress of unconfined and confined concrete, respectively, $\varepsilon_{\mathrm{ct}}$ and $f_{\mathrm{ct}}$ are the peak tensile strain and stress of concrete, respectively, $E_{\mathrm{c}}$ is the elastic modulus of concrete, and $E_{\text {sec }}$ is the secant modulus at the peak stress. The confinement effect provided by the stirrups is incorporated via the effective confinement index embedded in the model, which is determined based on the amount of transverse reinforcement, the spatial distribution of the transverse and longitudinal reinforcement, the transverse reinforcement yield strength, and the core concrete area [14]. A bilinear stress-strain relationship was adopted for steel reinforcing bars as shown in Figure 2(b), where $E_{\mathrm{s}}$ is the elastic modulus of steel, $\varepsilon_{\mathrm{sy}}$ and $\varepsilon_{\mathrm{su}}$ are the steel yield strain and fracture strain, respectively, and the hardening modulus of steel is taken as $0.01 E_{\mathrm{s}}$ to consider the effect of strain hardening [15].

Uniaxial loading was applied along the web direction as shown in Figure 1(b). Due to the difference in sectional deformation quantities of $\mathrm{T}$-shaped wall, moment-curvature analyses would be conducted twice in the flange-in-tension direction and flange-in-compression direction, respectively. The computation terminated when the longitudinal reinforcement reached the fracture strain or the confined 


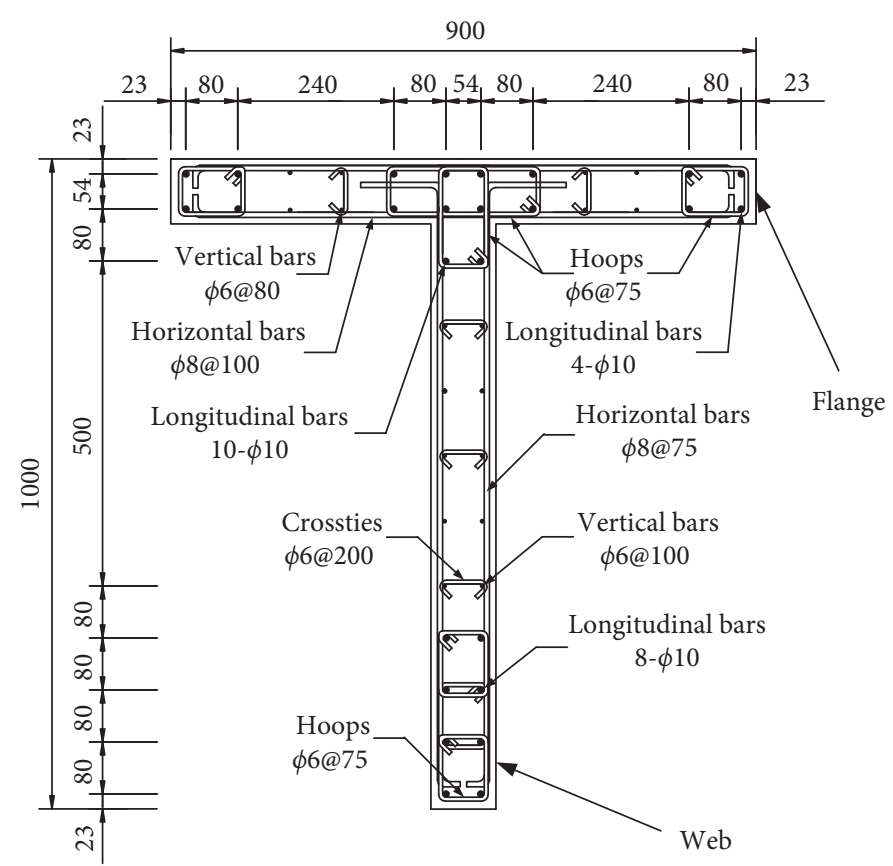

(a)

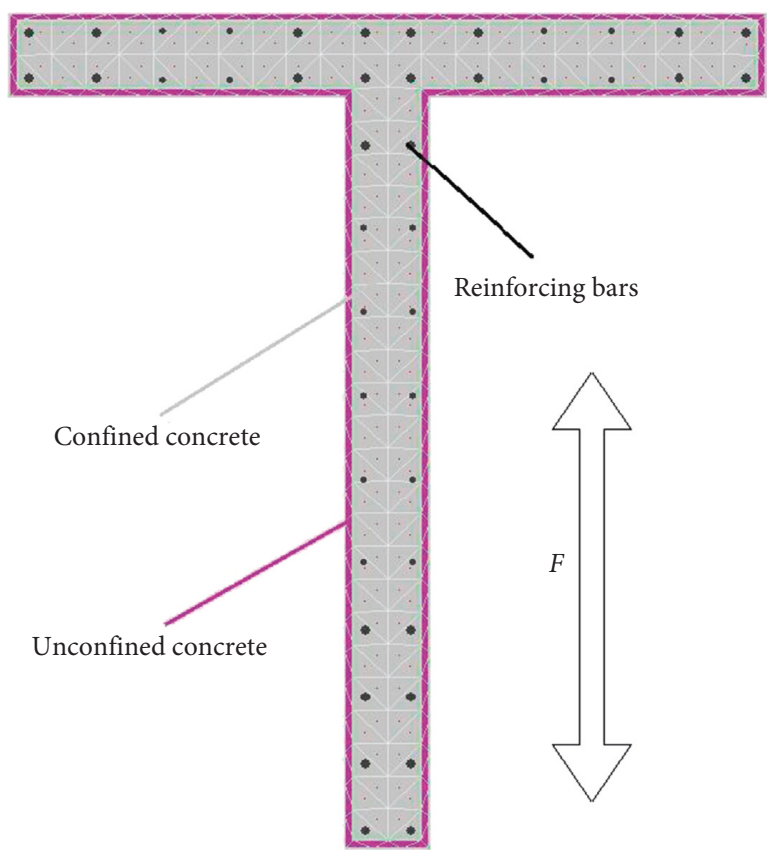

(b)

Figure 1: Prototype wall for numerical analysis. (a) Detail dimensions and reinforcement. (b) Finite element model.

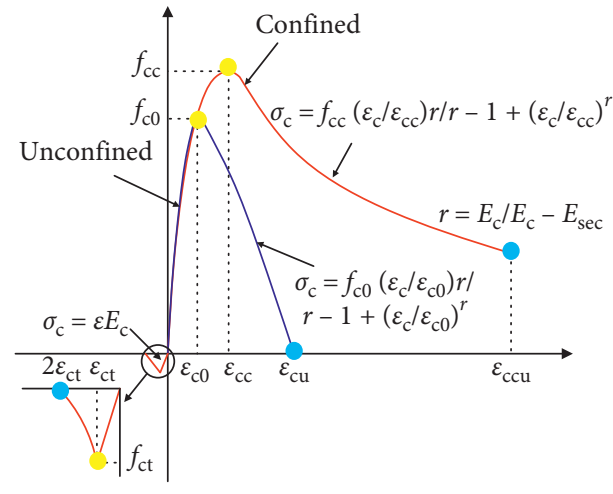

(a)



(b)

Figure 2: Material stress-strain relationships. (a) Concrete. (b) Reinforcing steel.

concrete reached the failure strain. The fracture strain of longitudinal reinforcement was taken as 0.075 according to Chinese design code [16], while the failure strain of confined concrete was defined for the fracture of the stirrup, which can be estimated by equating the strain energy capacity of the confining steel to the difference in energy between the confined concrete and the equivalent unconfined concrete [17].

2.2. Model Verification. Due to the difficulties in accurately measuring the curvatures during the test, to evaluate the capability of the numerical model, the moment-curvature curves calculated by XTRACT were transformed into lateral load-flexural displacement curves via the lumped plastic hinge model to compare with the experimental skeleton curves of the cyclic tests on T-shaped walls completed by the author [12], as shown in Figure 3. The reader is referred to the work by Brueggen [18] for the detailed calculation process using the lumped plastic hinge model. Excellent consistency is observed between the experimental results and the analytical predictions, which verifies the feasibility of XTRACT.

2.3. Parametric Analysis. Using the numerical model established above, a parametric analysis was conducted to investigate the variation of curvatures with different influencing factors and improve the precision of the curvature estimates for T-shaped wall cross-sections. The considered parameters include axial load ratio $n$, concrete strength $f_{\mathcal{c}}^{\prime}$, boundary longitudinal reinforcement ratio $\rho$, web distributed vertical reinforcement ratio $\rho_{\mathrm{w}}$, transverse reinforcement ratio $\rho_{\mathrm{v}}$, flange width to web height ratio $b_{\mathrm{f}} / l_{\mathrm{w}}$, 


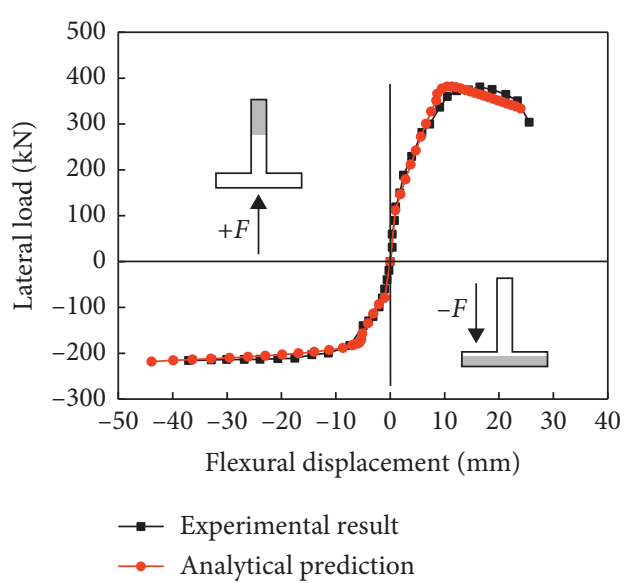

(a)

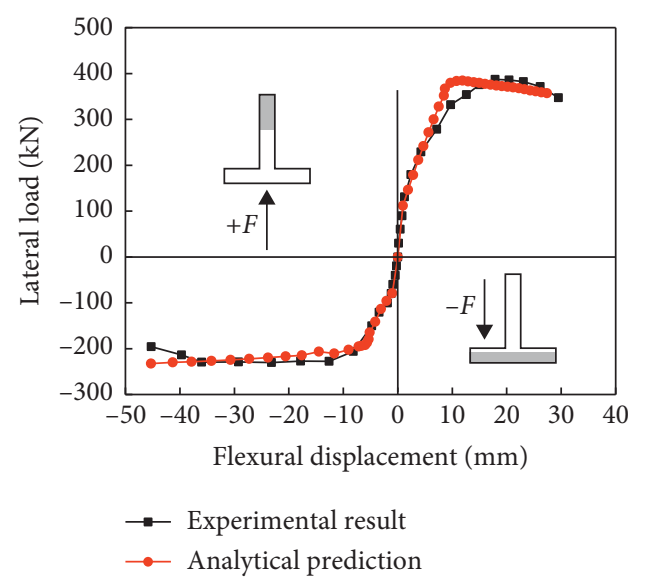

(b)

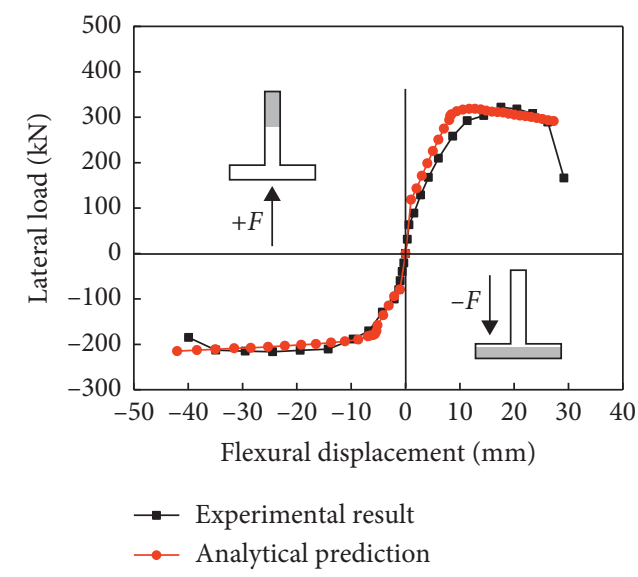

(c)

FIGURE 3: Experimental results compared with analytical predictions. (a) Specimen TW-1. (b) Specimen TW-3. (c) Specimen TW-4.

and web height to thickness ratio $l_{\mathrm{w}} / t$. The ranges of the parameters are summarized in Table 1 . The axial load ratio, defined as $n=P / A_{\mathrm{g}} \cdot f_{\mathrm{c}}^{\prime}\left(P=\right.$ axial load, $A_{\mathrm{g}}=$ gross area of the cross-section), was determined based on the mean strength of concrete $f_{\mathrm{c}}^{\prime}$. The concrete labelled C30, C35, C40, and C45 in Chinese design code was considered with mean cylinder strengths of $29.91 \mathrm{MPa}, \quad 34.88 \mathrm{MPa}, \quad 39.87 \mathrm{MPa}$, and 44.40 $\mathrm{MPa}$, respectively. The boundary longitudinal reinforcement ratio, defined as $\rho=A_{\mathrm{s}} / A_{\mathrm{g}}\left(A_{\mathrm{s}}=\right.$ area of longitudinal reinforcement), was changed by varying the diameter of longitudinal bars. The web distributed vertical reinforcement ratio, defined as $\rho_{\mathrm{w}}=A_{\mathrm{sw}} / A_{\mathrm{g}}\left(A_{\mathrm{sw}}=\right.$ area of web distributed vertical reinforcement), was changed by varying the diameter of distributed vertical bars. The transverse reinforcement ratio, defined as $\rho_{\mathrm{v}}=A_{\mathrm{sv}} / s t$ $\left(A_{\mathrm{sv}}=\right.$ area of transverse reinforcement), was changed by varying the hoop spacing $s$. The flange width to web height ratio was changed by varying the flange width, while the web height to thickness ratio was changed by varying the section thickness. Thus, the effect of the geometric parameters (flange width, web height, and section thickness) on the curvatures can be characterized by these two variables.
TABLE 1: Summary of the parameters examined.

\begin{tabular}{lc}
\hline Parameter & Value \\
\hline $\begin{array}{l}\text { Axial load ratio, } n \\
\text { Boundary longitudinal } \\
\text { reinforcement ratio, } \rho(\%)\end{array}$ & $0,0.05,0.1,0.15,0.2,0.25,0.3$ \\
$\begin{array}{l}\text { Web distributed vertical } \\
\text { reinforcement ratio, } \rho_{\mathrm{w}}(\%)\end{array}$ & $0.41,0.73,1.13,1.63,2.22$ \\
$\begin{array}{l}\text { Transverse reinforcement } \\
\text { ratio, } \rho_{\mathrm{v}}(\%)\end{array}$ & $0.87,1.04,1.30,1.73,2.60$ \\
$\begin{array}{l}\text { Concrete strength, } f_{\mathrm{c}}^{\prime}(\mathrm{MPa}) \\
\text { Flange width to web height } \\
\text { ratio, } b_{\mathrm{f}} / l_{\mathrm{w}}\end{array}$ & $29.91,34.88,39.87,44.40$ \\
Web height to thickness ratio, $l_{\mathrm{w}} / t$ & $7.14,8.33,10,12.5,16.7$ \\
\hline
\end{tabular}

\section{Analysis of Yield Curvature}

3.1. Definition of Yield Curvature. The above parametric analysis generated the moment-curvature curves under different influencing factors, and the yield curvature can be calculated from them for analysis. Generally, yield curvature is defined in two main ways: true yield curvature and effective yield curvature. The true yield curvature occurs for 
the lower of the curvatures corresponding to the first yield of longitudinal reinforcement and peak strain of unconfined concrete. The effective yield curvature is defined as the intersection of the line through the first yield point $\left(M_{\mathrm{y}}^{\prime}, \phi_{\mathrm{y}}^{\prime}\right)$ with the line drawn tangent to the moment-curvature curve [19]. The effective yield curvature was adopted in this paper because it facilitates the bilinear idealization of momentcurvature response. The bilinear approximation curve can speed up and simplify the calculations in nonlinear analysis and avoid step-by-step evaluation of the neutral axis position and consequent variation of the stiffness [11], which is of practical importance in structural design. Given the subjectivity in fitting the tangent line of the softened branch of moment-curvature curve, the effective yield curvature determined in this paper was based on the maximum flexural strength $M_{\max }$ (Figure 4).

$$
\phi_{\mathrm{y}}=\operatorname{Min}\left\{\phi_{\mathrm{yc}} \frac{M_{\max }}{M_{\mathrm{yc}}} ; \phi_{\mathrm{ys}} \frac{M_{\max }}{M_{\mathrm{ys}}}\right\},
$$

where $\phi_{\mathrm{yc}}$ and $M_{\mathrm{yc}}$ are the corresponding curvature and moment when the concrete reaches the peak strain of the unconfined concrete, i.e., $\varepsilon_{\mathrm{c} 0}=0.002 ; \phi_{\mathrm{ys}}$ and $M_{\mathrm{ys}}$ are the corresponding curvature and moment when the boundary longitudinal reinforcement reaches the yield strain. At lower axial load levels, the longitudinal bars may reach the yield strain first and thus dominate the yielding. At higher axial load levels, especially for the case with the flange in tension, the concrete at extreme compression fiber may reach the peak strain first, thus dominating the yielding.

3.2. Parametric Analysis on Yield Curvature. Previous studies on yield curvature have shown that the yield curvature is proportional to the steel yield strain $\varepsilon_{\mathrm{y}}$ and inversely proportional to the web height $l_{\mathrm{w}}[1,2]$. To facilitate the analysis, the dimensionless yield curvature coefficient $k_{\mathrm{y}}$ is introduced to quantify the effects of different parameters on the yield curvature:

$$
k_{\mathrm{y}}=\phi_{\mathrm{y}} l_{\mathrm{w}} / \varepsilon_{\mathrm{y}} .
$$

Moment-curvature analyses were performed for $\mathrm{T}$-shaped cross-sections under different parameters. When each parameter in Table 1 was examined, the values of the remaining parameters were fixed based on the experimental model. To explain the variation of the yield curvature with each parameter, Figure 5 shows the relationships among the yield curvature, neutral axis depth and strain. In Figure 5(a), when the tensile steel bars determine the yielding of the section, a larger neutral axis depth ought to produce a larger yield curvature. In Figure 5(b), when the compressive concrete determines the yielding of the section, a larger neutral axis depth leads to a smaller yield curvature. Therefore, the fundamental reason for the variation of the yield curvature with different parameters is the change in neutral axis depth under different factors.

Figures 6-11 show the variations in the yield curvature coefficient with the axial load ratio under the effects of different parameters. The hollow symbols in the figures

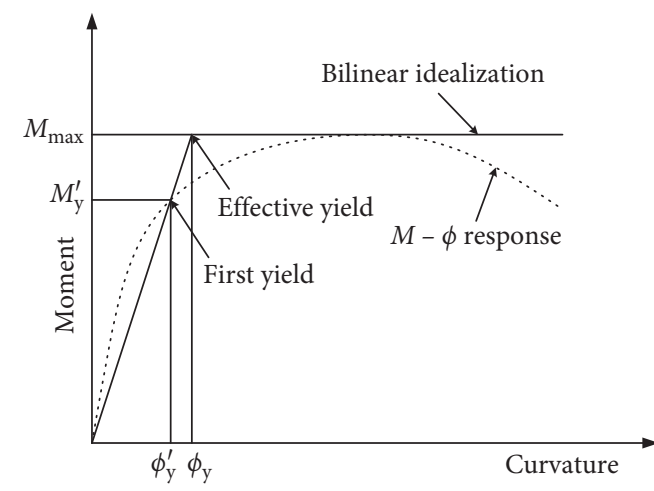

Figure 4: Definition of the effective yield curvature.

indicate that the yielding of the section is determined by the tensile steel bars, while the solid symbols indicate that the yielding of the section is determined by the compressive concrete. The factors that control the yielding of the section are different in two loading directions. In the flange-intension loading direction, yielding of the section is mostly determined by the tensile steel bars when the axial load ratio is less than 0.1 , while yielding of the section is determined by the compressive concrete when the axial load ratio is greater than or equal to 0.1 . In the flange-in-compression loading direction, yielding of the section is completely determined by the tensile steel bars due to its small neutral axis depth. The variation of the yield curvature with each parameter is analysed below.

3.2.1. Axial Load Ratio. The variation in the yield curvature with the axial load ratio is similar under different parameters, as shown in Figures 6-11. In the flange-in-tension loading direction, when the tensile steel bars determine the yielding of the section at lower axial load levels, the yield curvature increases with increasing axial load ratio due to the increased neutral axis depth. From another viewpoint, the increased axial load offsets part of the steel bar stress, which delays the yielding. When the compressive concrete determines the yielding of the section at higher axial load levels, the yield curvature decreases with increasing axial load ratio. This result is also attributed to the increase in neutral axis depth, which aggravates the increase in concrete strain. In the flange-in-compression loading direction, the yield curvature is nearly insensitive to the axial load ratio because increasing the axial load ratio hardly contributes to the increase in neutral axis depth due to the large flange width.

3.2.2. Boundary Longitudinal Reinforcement Ratio. As seen in Figure 6(a), in the flange-in-tension loading direction, the yield curvature increases with increasing longitudinal reinforcement ratio, especially at lower axial load levels. Increasing the longitudinal reinforcement ratio causes an increase in resultant force in both tension and compression zones of the section. At lower axial load levels, the neutral axis depth is relatively small, so the increase in longitudinal 


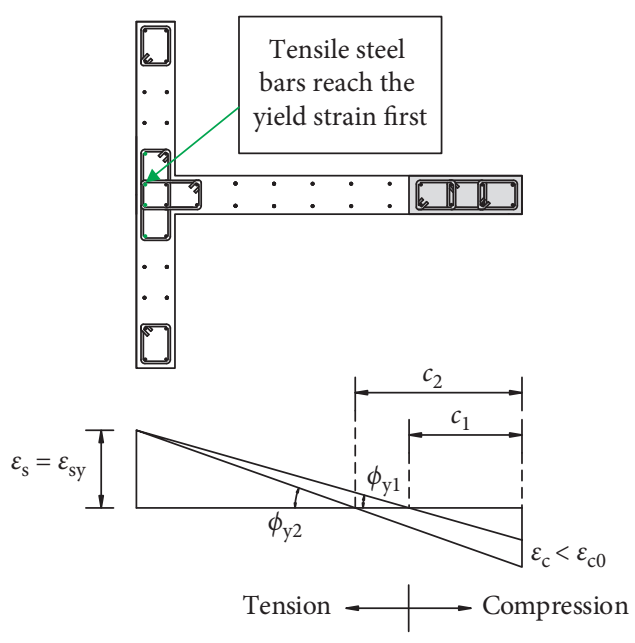

(a)



(b)

FIGURE 5: Relationships among the yield curvature, neutral axis depth, and strain. (a) Yielding determined by the tensile steel bars. (b) Yielding determined by the compressive concrete.

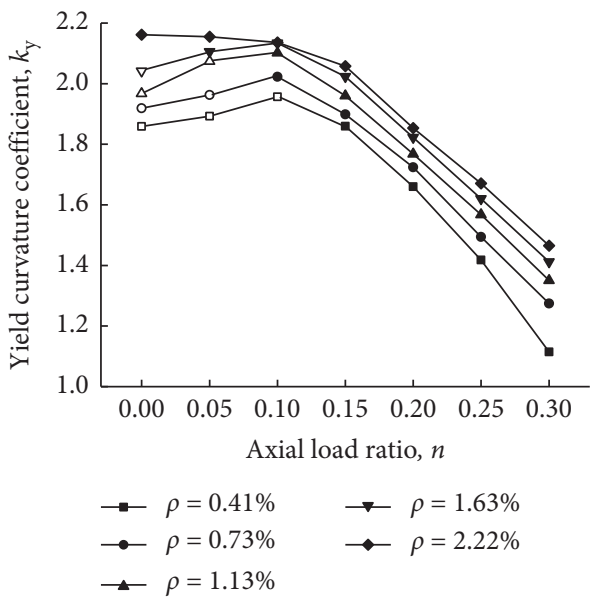

(a)

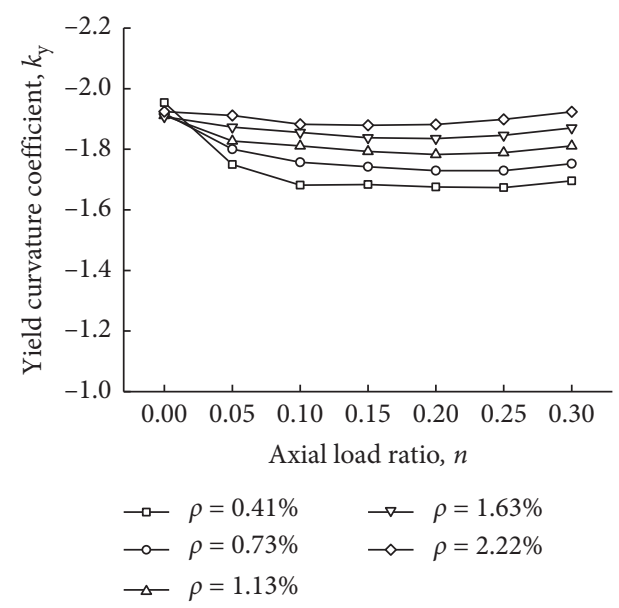

(b)

FIGURE 6: Variations in the yield curvature coefficient with the axial load ratio at different boundary longitudinal reinforcement ratios. (a) Flange in tension. (b) Flange in compression.

reinforcement ratio contributes more to the resultant force in the tension zone, which requires a greater neutral axis depth to balance the additional tension force. Hence, when the tensile steel bars determine the yielding of the section, the yield curvature increases with increasing longitudinal reinforcement ratio. At higher axial load levels, in contrast, the neutral axis depth is relatively large, and the increase in longitudinal reinforcement ratio contributes more to the resultant force in the compression zone, which requires a smaller neutral axis depth to balance the additional compression force. Hence, when the compressive concrete determines the yielding of the section, the yield curvature also increases with increasing longitudinal reinforcement ratio. From Figure 6(b), in the flange-in-compression loading direction, the yield curvature significantly increases with increasing longitudinal reinforcement ratio, which illustrates that the increase in longitudinal reinforcement ratio can effectively delay the yielding of the flanged walls.

\subsubsection{Web Distributed Vertical Reinforcement Ratio. As} seen in Figure 7(a), in the flange-in-tension loading direction, increasing the web distributed vertical reinforcement ratio leads to a small increase in yield curvature. In particular, when the compressive concrete determines the yielding at higher axial load levels, the yield curvature varies within $5 \%$ for the studied range of web distributed vertical reinforcement ratio. From Figure $7(\mathrm{~b})$, in the flange-incompression loading direction, the yield curvature significantly increases with increasing web distributed vertical reinforcement ratio. This result is attributed to the more obvious contribution of the increasing web distributed 




(a)



(b)

FIGURE 7: Variations in the yield curvature coefficient with the axial load ratio at different web distributed vertical reinforcement ratios. (a) Flange in tension. (b) Flange in compression.



(a)

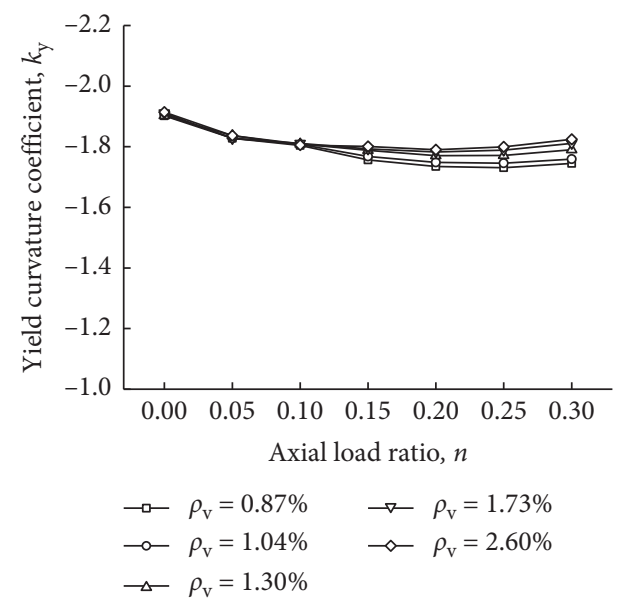

(b)

Figure 8: Variations in the yield curvature coefficient with the axial load ratio at different transverse reinforcement ratios. (a) Flange in tension. (b) Flange in compression.

vertical reinforcement ratio to the tension zone, which increases the neutral axis depth.

\subsubsection{Transverse Reinforcement Ratio. As seen in Figure 8,} for both cases with the flange in tension or flange in compression, the yield curvature slightly increases with increasing transverse reinforcement ratio, and the variation is relatively obvious only at higher axial load levels. Thus, increasing the transverse reinforcement ratio can also delay the yielding of the flanged walls, but it has a weaker effect on the yield curvature than the longitudinal reinforcement ratio.

3.2.5. Concrete Strength. As seen in Figure 9(a), in the flangein-tension loading direction, the yield curvature decreases with increasing concrete strength regardless of the factor that controls the yielding of the section. With the increase in concrete strength, the stress in compression zone increases under the same strain level, which decreases the neutral axis depth. On the other hand, increasing the concrete strength increases the axial load applied to the section at the same axial load ratio, which increases the neutral axis depth. Thus, the factor that dominates the variation of the neutral axis depth must be further discussed. By checking the position of the neutral axis at yielding from the numerical results, we have found that a higher concrete strength renders a smaller neutral axis depth for lower axial load levels, while it renders a larger neutral axis depth for higher axial load levels. Therefore, the yield curvature decreases with increasing concrete strength over the range of axial load ratios. From Figure 9(b), in the flange-in-compression loading direction, the concrete strength does not have a significant effect on the yield curvature. 


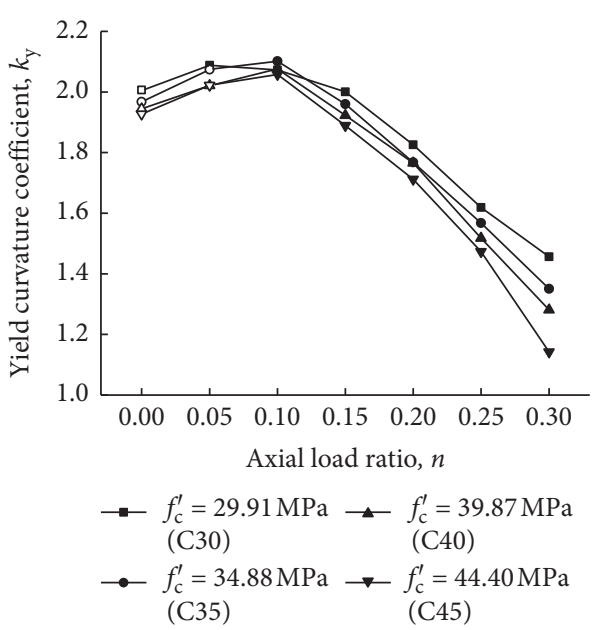

(a)

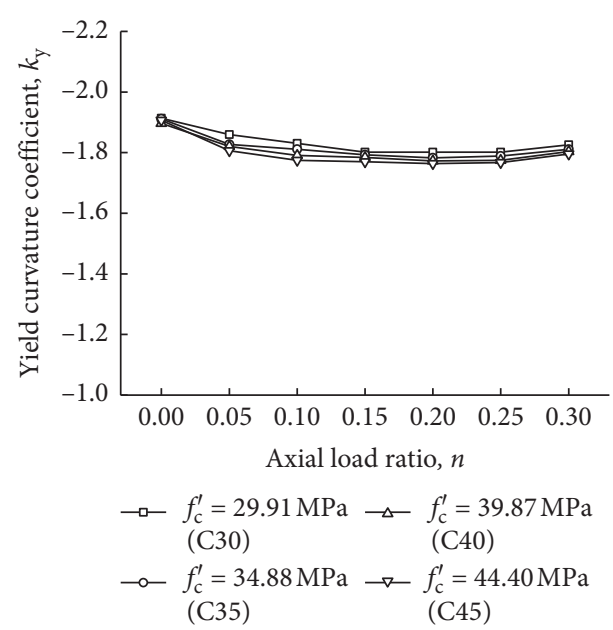

(b)

Figure 9: Variations in the yield curvature coefficient with the axial load ratio at different concrete strengths. (a) Flange in tension. (b) Flange in compression.

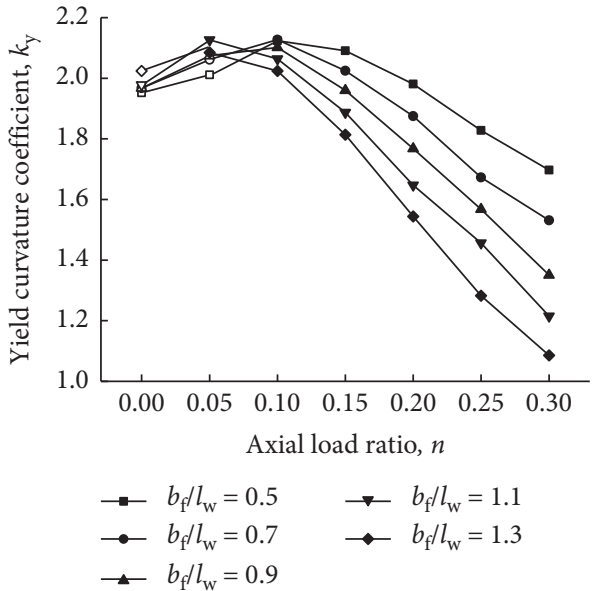

(a)



(b)

Figure 10: Variations in the yield curvature coefficient with the axial load ratio at different flange width to web height ratios. (a) Flange in tension. (b) Flange in compression.

3.2.6. Flange Width to Web Height Ratio. As seen in Figure 10(a), in the flange-in-tension loading direction, when the tensile steel bars determine the yielding of the section at lower axial load levels, the yield curvature increases with increasing flange width to web height ratio. However, when the compressive concrete determines the yielding of the section at higher axial load levels, the yield curvature decreases with increasing flange width to web height ratio. This is all due to the increase in flange width which increases the neutral axis depth. From Figure 10(b), in the flange-in-compression loading direction, increasing the web distributed vertical reinforcement ratio causes a small decrease in yield curvature.
3.2.7. Web Height to Thickness Ratio. As seen in Figure 11, the curves for the yield curvature coefficient versus axial load ratio at different web height to thickness ratios nearly coincide for both flange in tension and flange in compression, which indicates that the changes in section thickness have little effect on the yield curvature.

3.3. Simplified Calculation of Yield Curvature. Through the quantitative parametric analysis on the yield curvature, the main parameters affecting the yield curvature of $\mathrm{T}$-shaped walls with the flange in tension are identified as the axial load ratio, longitudinal reinforcement ratio, and flange width to 


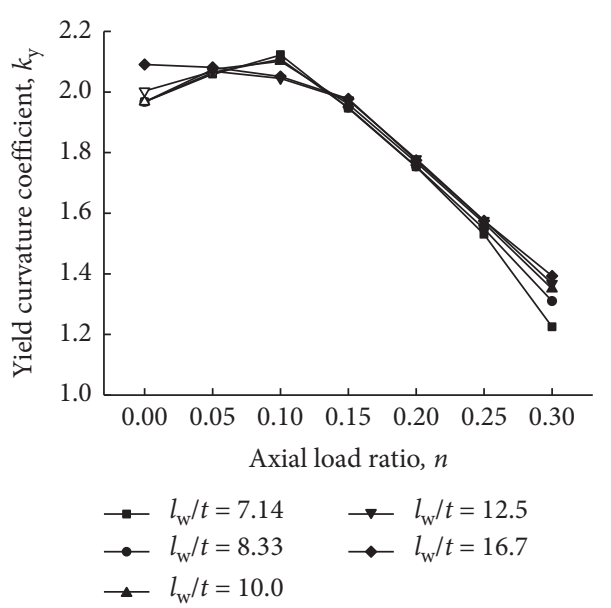

(a)

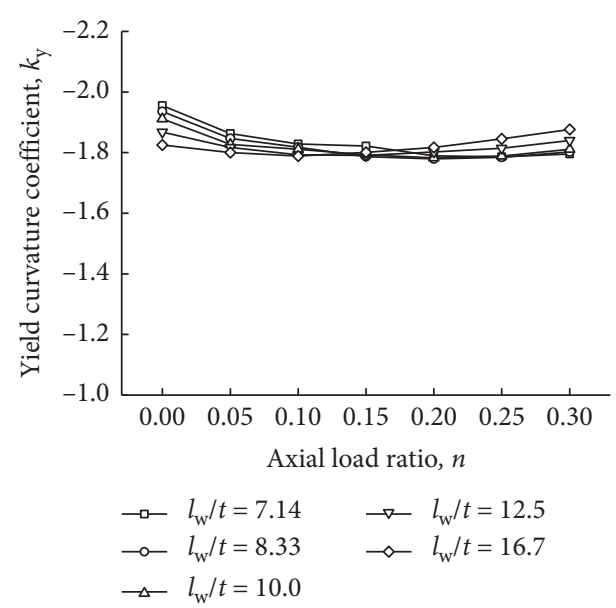

(b)

FiguRE 11: Variations in the yield curvature coefficient with the axial load ratio at different web height to thickness ratios. (a) Flange in tension. (b) Flange in compression.

web height ratio, while the main parameters affecting the yield curvature in the flange-in-compression loading direction are the longitudinal reinforcement ratio and web distributed vertical reinforcement ratio. However, the parametric analysis was conducted with the considered parameters combined orthogonally; that is to say, each level of each influencing factor is analyzed only once, without considering the interlacing of the levels between different influencing factors. For example, when examining the effect of the concrete strength on yield curvature, the five levels (values) of concrete were analyzed separately, while the values of the remaining parameters were fixed based on the experimental model. Thus the effect of the concrete strength has not been examined with the values of the remaining parameters beyond the experimental model. The above "orthogonal analysis" was suitable for selecting the main parameters due to its low computational cost. To more accurately fit the calculation formulas of the yield curvature, a "comprehensive analysis" combining all levels among different influencing factors was supplemented for these main parameters. In total, $175 \mathrm{~T}$-shaped cross-sections under different combinations of the main parameters were analysed for the case with the flange in tension, and 20 sections were analysed for the case with the flange in compression. Due to space restrictions, the extensive analytical results for different wall sections are no longer listed here.

The results show that in the flange-in-tension loading direction, when the axial load ratio is greater than or equal to 0.1 , the dimensionless yield curvature coefficient is approximately linear with each parameter, and the effect of each parameter on yield curvature coefficient is independent of the others. Thus, a multiple linear function can be used for regression. When the axial load ratio is less than 0.1, the yield curvature hardly varies in poor regularity with each parameter and is slightly smaller than the value for the axial load ratio of 0.1. Considering that the axial load ratio of shear walls at the bottom of an actual structure is generally greater than 0.1 , for the convenience of computing, the yield curvature with the axial load ratio less than 0.1 is assumed to be equal to the predicted value for the axial load ratio of 0.1. In the flange-in-compression loading direction, a multiple linear function was also employed for regression.

Through the regression analyses, the dimensionless yield curvature coefficients for the flange in tension and in compression are expressed as follows:

$$
\begin{aligned}
& k_{\mathrm{yFiT}}=2.77-3.66 n+11.17 \rho-0.49 \frac{b_{\mathrm{f}}}{l_{\mathrm{w}}}, \\
& k_{\mathrm{yFiC}}=1.61+8.91 \rho+14.92 \rho_{\mathrm{w}} .
\end{aligned}
$$

The coefficients of determination $\left(R^{2}\right)$ used to evaluate the general goodness of fit for equations (3) and (4) are 0.93 and 0.91 , respectively, which indicates that perfect matching can be achieved with the multiple linear function. Moreover, Figure 12 compares the yield curvature coefficients calculated from the moment-curvature analyses to the values predicted by the proposed equations. From the statistics such as the mean and the standard deviation of the prediction-to-calculation ratio, equations (3) and (4) can predict the yield curvature coefficients with sufficient accuracy.

Then, substituting equations (3) and (4) into equation (2), we obtain the formulas to calculate the yield curvatures for the flange in tension and in compression:

$$
\begin{aligned}
\phi_{\mathrm{yFiT}} & =\frac{\varepsilon_{\mathrm{y}}}{l_{\mathrm{w}}}\left(2.77-3.66 n+11.17 \rho-0.49 \frac{b_{\mathrm{f}}}{l_{\mathrm{w}}}\right), \\
\phi_{\mathrm{yFiC}} & =\frac{\varepsilon_{\mathrm{y}}}{l_{\mathrm{w}}}\left(1.61+8.91 \rho+14.92 \rho_{w}\right) .
\end{aligned}
$$

Compared with previous research results, the proposed formulas distinguish the cases with the flange in tension and in compression and rationally reflect the effects of the involved design parameters on the yield curvature. 


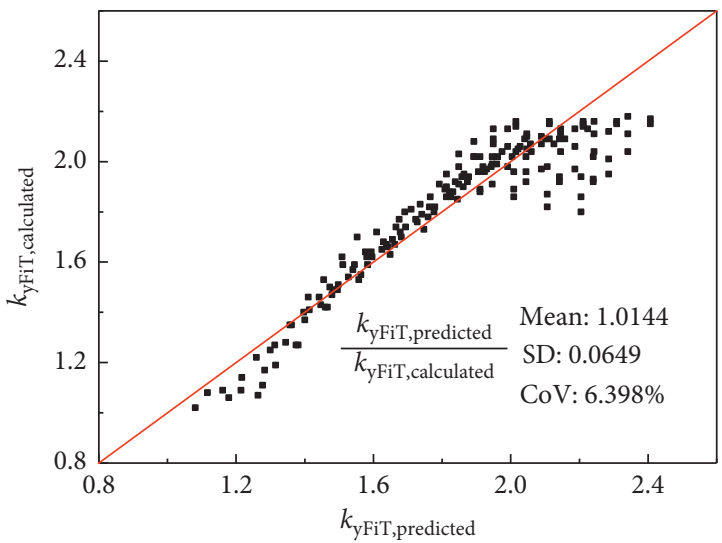

(a)

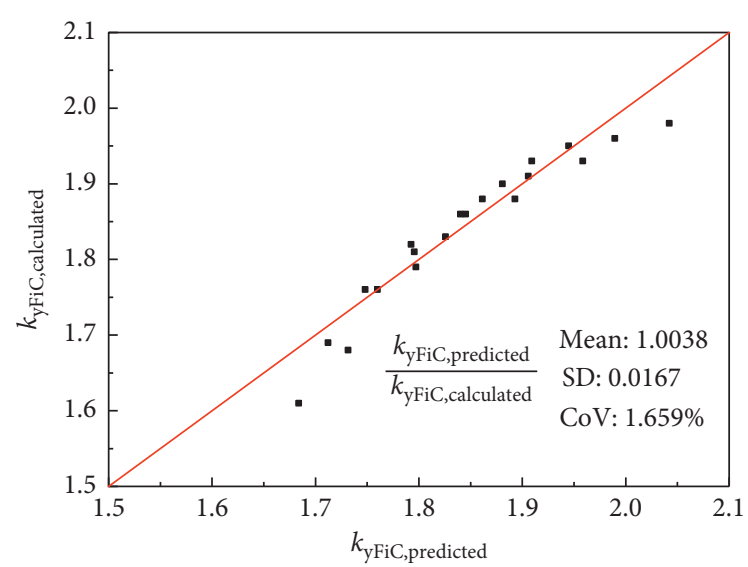

(b)

FIGURE 12: Calculated and predicted yield curvature coefficients. (a) Flange in tension. (b) Flange in compression.

3.4. Verification. To further verify the accuracy of the proposed formulas to estimate the yield curvature, the yield displacements calculated from the yield curvatures are compared with the experimental results of asymmetric flanged walls tested by Wang et al. [12] and Thomsen and Wallace [20], as listed in Table 2. These two experiments were conducted to investigate the influence of detailing at the boundaries on deformation properties of T-shaped walls, and all the test specimens failed in flexure. The yield displacement of a cantilever is often simply estimated based on a triangular curvature distribution [21]:

$$
\Delta_{\mathrm{y}}=\frac{1}{3} \phi_{\mathrm{y}} H^{2}
$$

where $H$ is the wall height. Table 2 shows that the calculated yield displacements are generally smaller than the experimental values. This is because when calculating the yield displacement through equation (6), only the flexural deformations are considered, while the shear deformations and strain-penetration-induced deformations are neglected. In the flange-in-tension loading direction, the predicted values differ within $10 \%$ from the experimental values except for specimen TW-4; the larger experimental yield displacement of specimen TW-4 results from the unexpected cracks that appear on the surface of the foundation at the initial stage of loading. In the flange-in-compression loading direction, the experimental values generally exceed the predicted values by $10 \%$, which is attributed to the higher proportion of shear deformation for the case with the flange in compression. In general, the experimental values are close to the calculated values, which verify the accuracy of the proposed formulas and provides the basis to estimate the curvature ductility.

\section{Analysis of Ultimate Curvature}

4.1. Definition of Ultimate Curvature. Based on the momentcurvature curves derived from the parametric analysis, the ultimate curvatures can be calculated for analysis. For sections with different geometries, reinforcement content, and axial load ratios, the ultimate limit state is defined as the smallest value of the curvatures in the following four cases:
(1) The moment resistance of the section decreases to $85 \%$ of the maximum moment capacity

(2) The core concrete achieves the ultimate compressive strain limit, which is estimated as $\varepsilon_{\mathrm{ccu}}=0.018$ according to Smyrou et al. [1]

(3) The longitudinal tensile bars achieve the ultimate tensile strain limit, which is estimated as $\varepsilon_{\text {su }}=0.06$ according to Smyrou et al. [1]

(4) The longitudinal compressive bars achieve the critical buckling strain, which is estimated as $\varepsilon_{\mathrm{b}}=42200(s / d)^{-0.412}$ according to Cao et al. [22]

where $d$ is the diameter of the longitudinal reinforcement. From the experimental research on T-shaped and L-shaped walls completed by the author [12], conditions 2 and 3 are the controlling factors of the flange-in-tension direction and flangein-compression direction, respectively, and condition 4 is ineffective for well-confined boundary elements.

4.2. Parametric Analysis on Ultimate Curvature. To facilitate the analysis, the dimensionless ultimate curvature coefficient $k_{\mathrm{u}}$ is also introduced to quantify the effects of different parameters on the ultimate curvature:

$$
k_{\mathrm{u}}=1000 \phi_{\mathrm{u}} l_{\mathrm{w}} .
$$

Figures 13-18 show the variations in the ultimate curvature coefficient with the axial load ratio under the effects of different parameters. The involved parameters do not significantly affect the ultimate curvature in the flange-in-compression loading direction, among which the effects of the axial load ratio, flange width to web height ratio, and web height to thickness ratio are relatively prominent. The ultimate curvature increases with increasing axial load ratio and decreases with increasing flange width to web height ratio and web height to thickness ratio. These variations can also be interpreted by the variation of the neutral axis depth under different parameters, as in the case of the yield curvature in Figure 5 . 
TABLE 2: Comparison between measured and predicted yield displacements.

\begin{tabular}{|c|c|c|c|c|c|c|c|}
\hline & \multirow{2}{*}{ Specimen } & \multicolumn{3}{|c|}{$\Delta_{\mathrm{y}}$ (flange in tension) } & \multicolumn{3}{|c|}{$\Delta_{\mathrm{y}}$ (flange in compression) } \\
\hline & & Measured (mm) & Predicted $(\mathrm{mm})$ & Error $(\%)$ & Measured (mm) & Predicted $(\mathrm{mm})$ & Error $(\%)$ \\
\hline \multirow{5}{*}{ Wang et al. [12] } & TW-1 & 8.70 & 9.59 & -10.23 & 9.40 & 8.24 & 12.34 \\
\hline & TW-2 & 8.80 & 9.59 & -8.98 & 9.30 & 8.24 & 11.40 \\
\hline & TW-3 & 10.60 & 9.70 & 8.49 & 10.10 & 8.33 & 17.52 \\
\hline & TW-4 & 11.50 & 9.45 & 17.83 & 9.50 & 8.13 & 14.42 \\
\hline & LW-1 & 10.40 & 9.46 & 9.04 & 9.40 & 8.14 & 13.40 \\
\hline \multirow{2}{*}{ Thomsen and Wallace [20] } & TW-1 & 17.75 & 16.66 & 6.14 & 11.16 & 13.20 & -18.28 \\
\hline & TW-2 & 18.06 & 16.69 & 7.59 & 13.57 & 13.35 & 1.62 \\
\hline
\end{tabular}

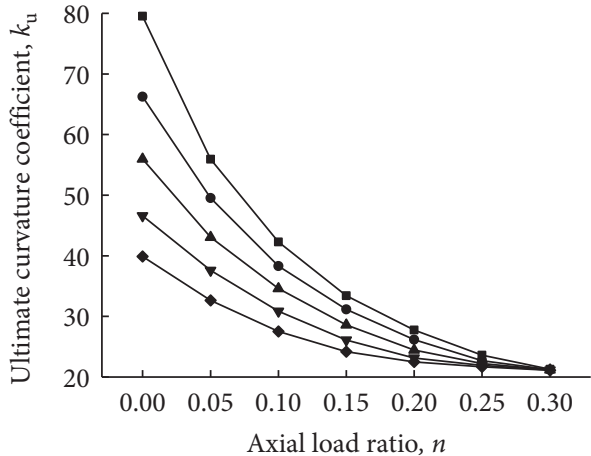

$$
\begin{aligned}
& \longrightarrow \rho=0.41 \% \quad \rightarrow \rho=1.63 \% \\
& \longrightarrow \rho=0.73 \% \\
& \multimap \rho=1.13 \%
\end{aligned}
$$

(a)

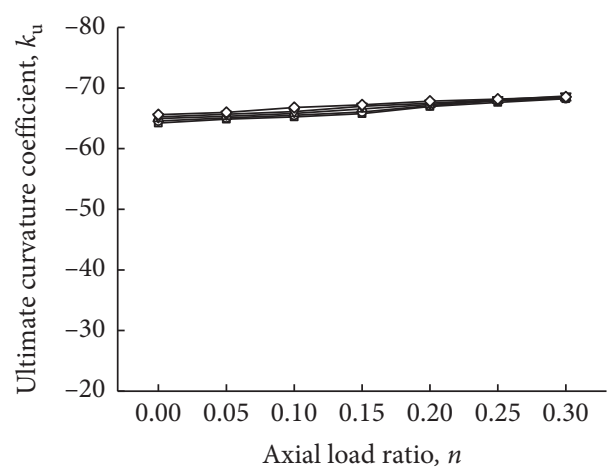

$$
\begin{aligned}
& \rightarrow \rho=0.41 \% \quad \rightarrow \rho=1.63 \% \\
& \multimap \rho=0.73 \% \quad \multimap \rho=2.22 \% \\
& \neg-\rho=1.13 \%
\end{aligned}
$$

(b)

FIGURE 13: Variations in the ultimate curvature coefficient with the axial load ratio at different boundary longitudinal reinforcement ratios. (a) Flange in tension. (b) Flange in compression.

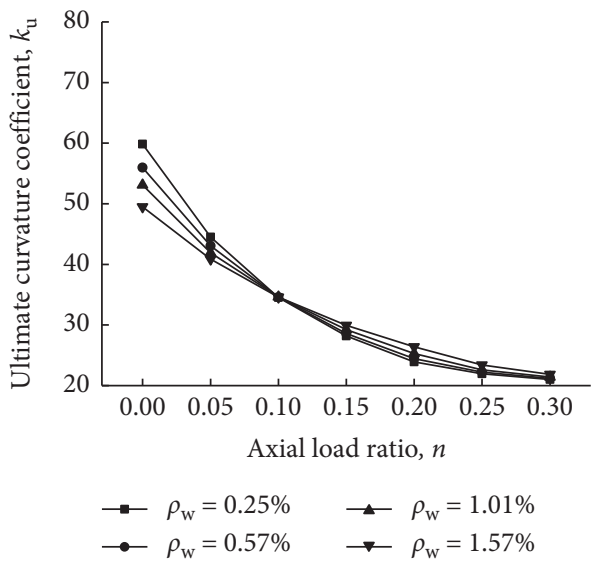

(a)

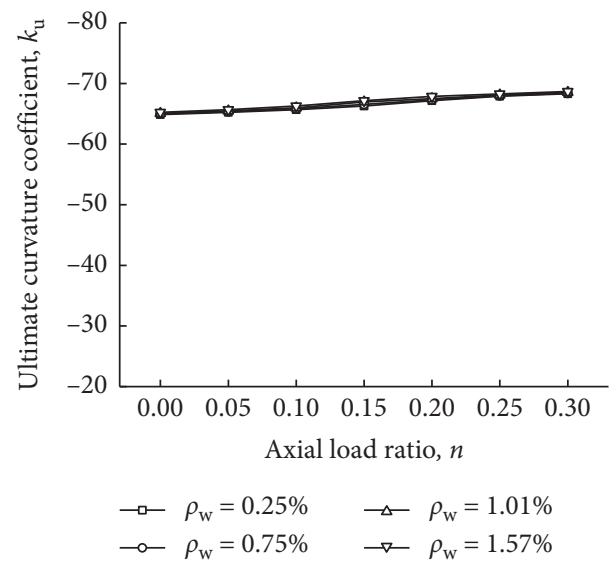

(b)

FiguRE 14: Variations in the ultimate curvature coefficient with the axial load ratio at different web distributed vertical reinforcement ratios. (a) Flange in tension. (b) Flange in compression.

In the flange-in-tension loading direction, the ultimate curvatures cover a wide spectrum, and the variation trends are complicated. In general, all involved parameters have significant effects on the ultimate curvature except for the web distributed vertical reinforcement ratio and concrete strength.
The ultimate curvature obviously decreases with the increases in axial load ratio, longitudinal reinforcement ratio, flange width to web height ratio, and web height to thickness ratio, all of which are attributed to the increased neutral axis depth that renders the concrete to reach its ultimate compressive 


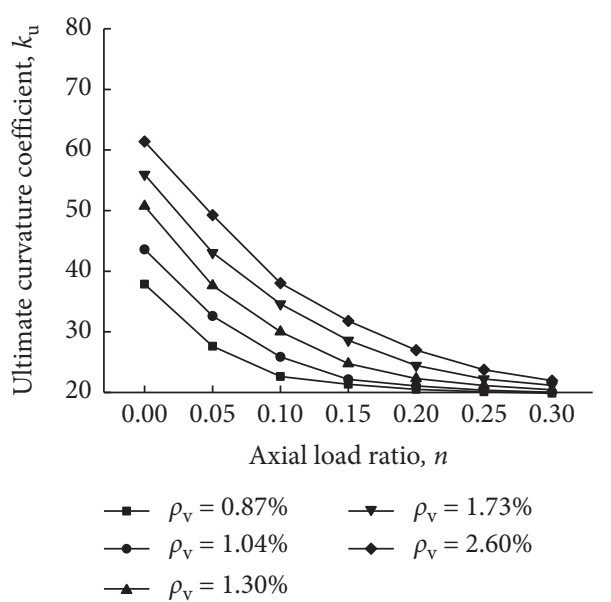

(a)

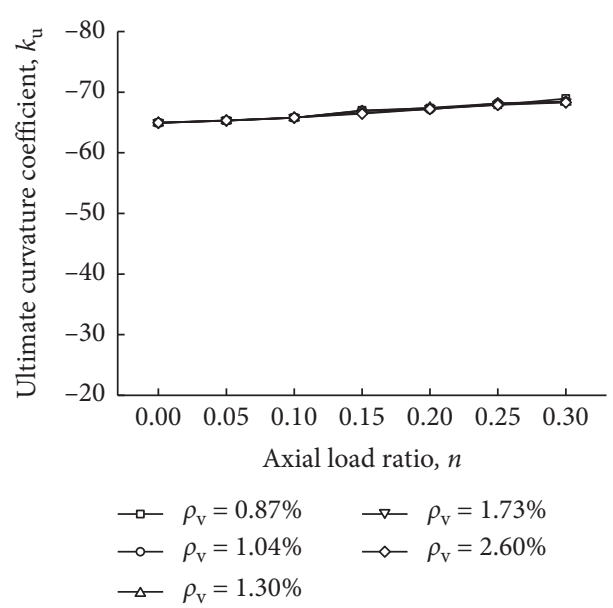

(b)

FIGURE 15: Variations in the ultimate curvature coefficient with the axial load ratio at different transverse reinforcement ratios. (a) Flange in tension. (b) Flange in compression.

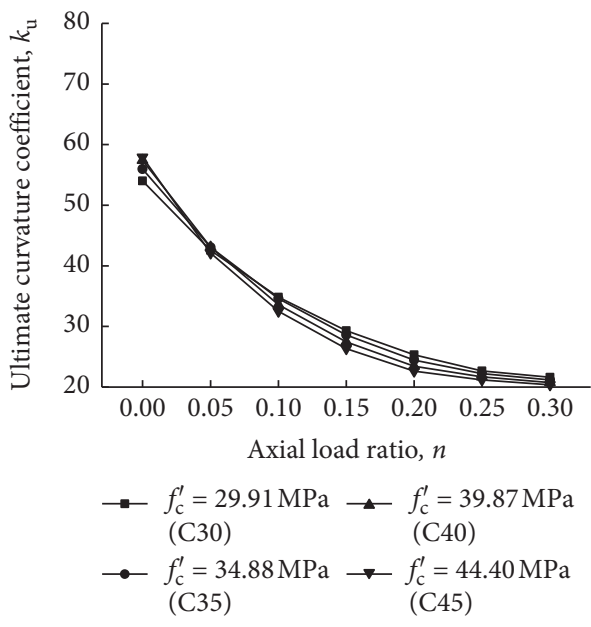

(a)

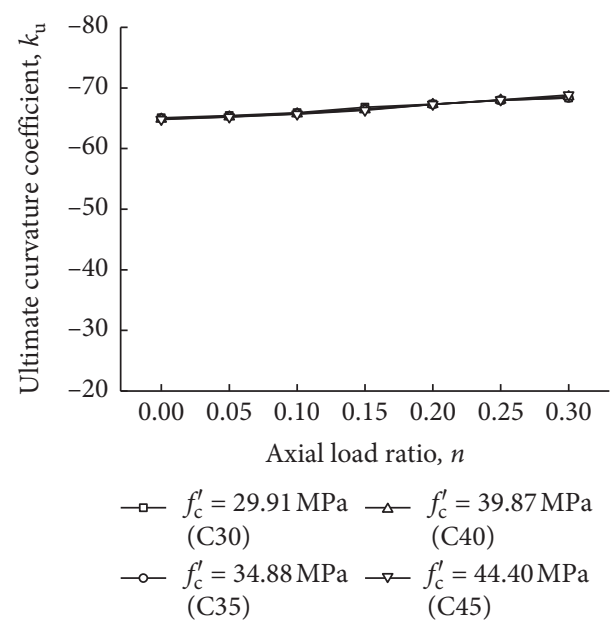

(b)

Figure 16: Variations in the ultimate curvature coefficient with the axial load ratio at different concrete strengths. (a) Flange in tension. (b) Flange in compression.

strain earlier. Meanwhile, the ultimate curvature increases with increasing transverse reinforcement ratio because the enhancement of the transverse constraint improves the ultimate compressive strain of the core concrete and delays the damage of the section.

4.3. Simplified Calculation of Ultimate Curvature. Based on the main parameters that affect the ultimate curvature derived through the "orthogonal analysis," a "comprehensive analysis" was further supplemented to improve the precision of the curvature estimates. In total, 4375 T-shaped crosssections were analysed for the case with the flange in tension, and 175 sections were analysed for the case with the flange in compression. Due to space restrictions, the extensive analytical results for different wall sections are no longer listed here.

The results show that, in the flange-in-tension loading direction, the dimensionless ultimate curvature coefficient first rapidly decreases and subsequently slowly decreases with the increase in axial load ratio, which is consistent with the exponential function distribution. While the ultimate curvature coefficient is approximately linear with other parameters, overall, the effect of each parameter on ultimate curvature coefficient is independent of the others, so a combination of a multiple linear function and an exponential function can be used for regression. In the flange-incompression loading direction, a multiple linear function was used for regression due to the linear relation between the ultimate curvature coefficient and each parameter. 


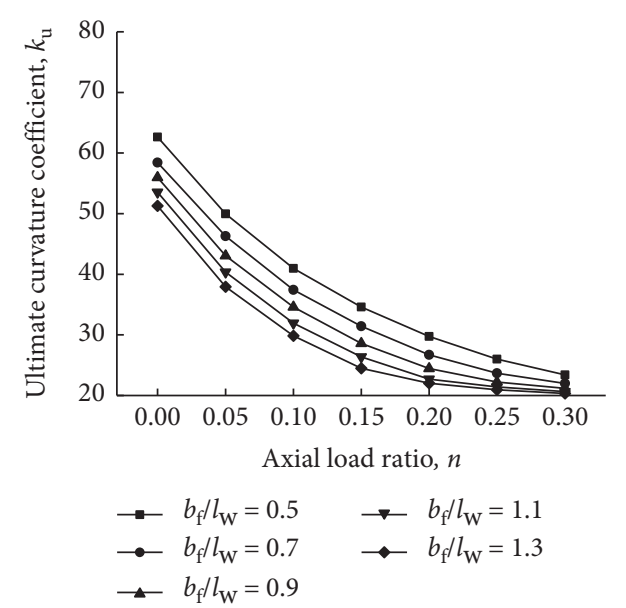

(a)

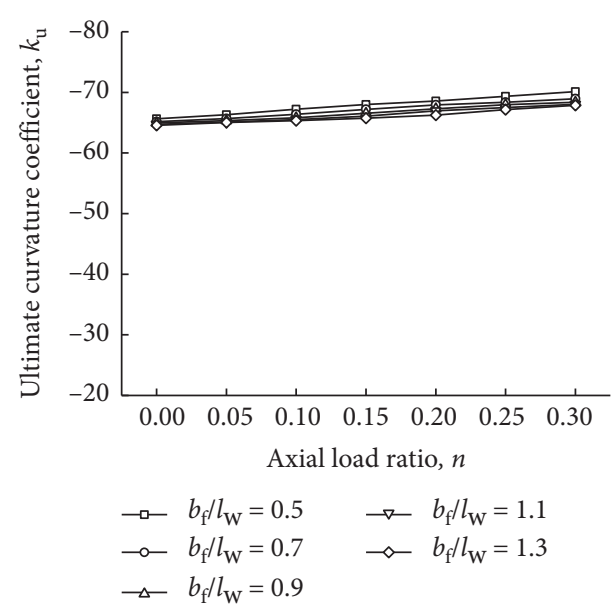

(b)

FIGURE 17: Variations in the ultimate curvature coefficient with the axial load ratio at different flange width to web height ratios. (a) Flange in tension. (b) Flange in compression.

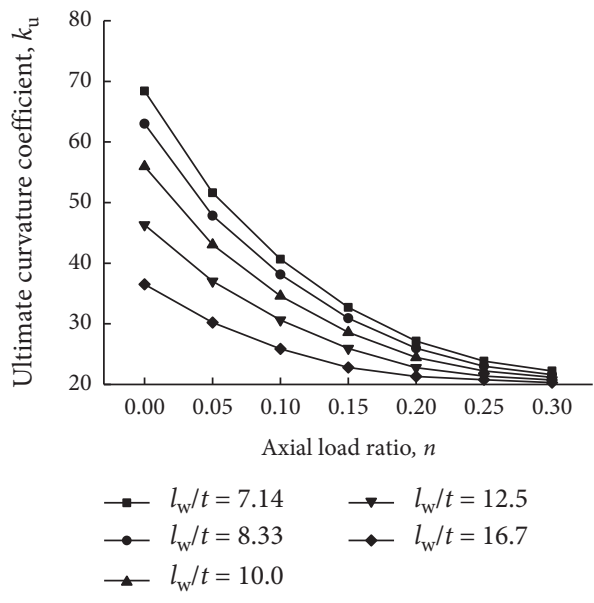

(a)

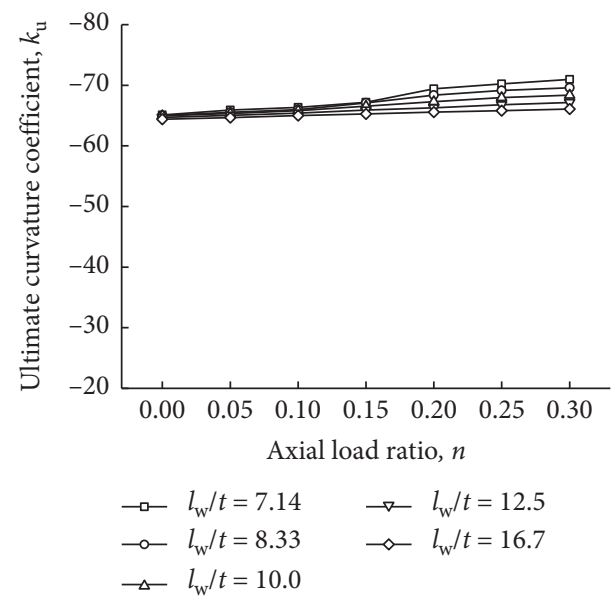

(b)

Figure 18: Variations in the ultimate curvature coefficient with the axial load ratio at different web height to thickness ratios. (a) Flange in tension. (b) Flange in compression.

Through regression analyses, the expressions of the dimensionless ultimate curvature coefficient for the flange in tension and in compression are as follows:

$$
\begin{aligned}
k_{\mathrm{uFiT}}= & 37.97+37.73 e^{-8.83 n}-751.68 \rho-11.33 \frac{b_{\mathrm{f}}}{l_{\mathrm{w}}} \\
& +804.56 \rho_{\mathrm{v}}-1.36 \frac{l_{\mathrm{w}}}{t}, \\
k_{\mathrm{uFiC}}= & 68.65+12.67 n-2.31 \frac{b_{\mathrm{f}}}{l_{\mathrm{w}}}-0.27 \frac{l_{\mathrm{w}}}{t} .
\end{aligned}
$$

The coefficients of determination $\left(R^{2}\right)$ to fit equations (8) and (9) based on the above 4550 working conditions are beyond 0.9 , which demonstrates the rationality of the adopted functions. Figure 19 compares the ultimate curvature coefficients calculated from the moment-curvature analyses to the values predicted by the proposed equations. The statistics of the prediction-to-calculation ratio further verifies the accuracy of equations (8) and (9).

Then, substituting equations (8) and (9) into equation (7), we obtain the formulas to calculate the ultimate curvatures for the flange in tension and in compression:

$$
\begin{aligned}
\phi_{\mathrm{uFiT}}= & \frac{1}{1000 l_{\mathrm{w}}}\left(37.97+37.73 e^{-8.83 n}-751.68 \rho\right. \\
& \left.-11.33 \frac{b_{\mathrm{f}}}{l_{\mathrm{w}}}+804.56 \rho_{\mathrm{v}}-1.36 \frac{l_{\mathrm{w}}}{t}\right), \\
\phi_{\mathrm{uFiC}}= & \frac{1}{1000 l_{\mathrm{w}}}\left(68.65+12.67 n-2.31 \frac{b_{\mathrm{f}}}{l_{\mathrm{w}}}-0.27 \frac{l_{\mathrm{w}}}{t}\right) .
\end{aligned}
$$






(a)

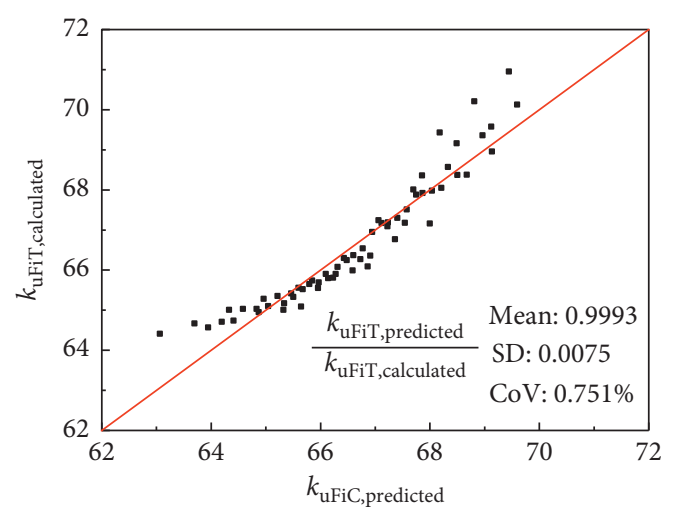

(b)

Figure 19: Calculated and predicted ultimate curvature coefficients. (a) Flange in tension. (b) Flange in compression.

TABle 3: Comparison between the measured displacement ductility and predicted displacement ductility.

\begin{tabular}{|c|c|c|c|c|c|c|c|}
\hline & \multirow{2}{*}{ Specimen } & \multicolumn{3}{|c|}{$\mu_{\Delta}$ (flange in tension) } & \multicolumn{3}{|c|}{$\mu_{\Delta}$ (flange in compression) } \\
\hline & & Measured (mm) & Predicted $(\mathrm{mm})$ & Error (\%) & Measured (mm) & Predicted $(\mathrm{mm})$ & Error $(\%)$ \\
\hline \multirow{5}{*}{ Wang et al. [12] } & TW-1 & 2.86 & 3.10 & -8.39 & 4.90 & 5.93 & -21.02 \\
\hline & TW-2 & 2.75 & 3.10 & -12.73 & 5.04 & 5.93 & -17.66 \\
\hline & TW-3 & 3.05 & 3.44 & -12.79 & 5.36 & 5.89 & -9.89 \\
\hline & TW-4 & 2.45 & 3.29 & -34.29 & 4.91 & 6.01 & -22.40 \\
\hline & LW-1 & 2.72 & 3.27 & -20.22 & 4.91 & 6.00 & -22.20 \\
\hline \multirow{2}{*}{ Thomsen and Wallace [20] } & TW-1 & 2.56 & 2.93 & -14.45 & 5.26 & 6.22 & -18.25 \\
\hline & TW-2 & 4.55 & 4.19 & 7.91 & 6.55 & 6.29 & 3.97 \\
\hline
\end{tabular}

\section{Estimates of Ductility Capacity}

The derivation of the expressions to estimate the curvatures at the yield and ultimate limit state enables the computation of the ductility capacity. The curvature ductility for the flange in tension can be calculated as follows:

$$
\mu_{\phi \mathrm{FiT}}=\frac{\phi_{\mathrm{uFiT}}}{\phi_{\mathrm{yFiT}}}=\frac{37.97+37.73 e^{-8.83 n}-751.68 \rho-11.33\left(b_{\mathrm{f}} / l_{\mathrm{w}}\right)+804.56 \rho_{\mathrm{v}}-1.36\left(l_{\mathrm{w}} / t\right)}{1000 \varepsilon_{\mathrm{y}}\left(2.77-3.66 n+11.17 \rho-0.49\left(b_{\mathrm{f}} / l_{\mathrm{w}}\right)\right)} .
$$

The curvature ductility for the flange in compression can be calculated as follows:

$$
\mu_{\phi \mathrm{FiC}}=\frac{\phi_{\mathrm{uFiC}}}{\phi_{\mathrm{yFiC}}}=\frac{68.65+12.67 n-2.31\left(b_{\mathrm{f}} / l_{\mathrm{w}}\right)-0.27\left(l_{\mathrm{w}} / t\right)}{1000 \varepsilon_{y}\left(1.61+8.91 \rho+14.92 \rho_{\mathrm{w}}\right)} .
$$

Based on the established formulas of the curvature ductility, by neglecting the effects of shear deformations and strain-penetration-induced deformations, we calculate the displacement ductility of shear walls using the equation proposed by Park and Paulay [23]:

$$
\mu_{\Delta}=3\left(\frac{l_{\mathrm{p}}}{h_{\mathrm{e}}}\right)\left[1-\frac{l_{\mathrm{p}}}{\left(2 h_{\mathrm{e}}\right)}\right]\left(\mu_{\phi}-1\right)+1,
$$

where $h_{\mathrm{e}}$ is the effective height of the wall and $l_{\mathrm{p}}$ is the plastic hinge length, which can be estimated as $l_{\mathrm{p}}=(0.2+$ $\left.0.044 H / l_{\mathrm{w}}\right) l_{\mathrm{w}}$ according to Thomsen and Wallace [20]. To verify the accuracy of the proposed formulas to estimate the ductility capacity, the displacement ductility of asymmetric flanged walls is calculated to compare with the experimental results from Wang et al. [12] and Thomsen and Wallace [20], as listed in Table 3.

Table 3 shows that the calculated displacement ductility is generally greater than the experimental values, especially for the case with the flange in compression, where the predicted values exceed the test values by approximately $20 \%$. This is primarily because the proposed method in this paper can only obtain the bending ductility, while the shear effect will inevitably reduce the displacement ductility of the walls. The larger deviation of specimen TW-4 is due to its higher predicted yield displacement as shown previously. Furthermore, in the flange-in-compression loading direction, failure of the experimental specimens was controlled by the fracture of the buckled longitudinal bars at the free end of the web, but the monotonic loading scheme in the 
simulation cannot accurately consider the decrease in ultimate tensile strain due to the buckling of the longitudinal bars, so it overestimates the ultimate displacement and ductility capacity. In general, the proposed method can reasonably predict the ductility capacity of asymmetric flanged walls and provide a basis for the ultimate deformation capacity calculation.

\section{Conclusions}

Moment-curvature analyses were performed for a series of T-shaped wall cross-sections with regard to their asymmetric properties. All parameters, including the axial load ratio, reinforcement content, material properties, and geometric parameters, that affect the estimate of curvatures at the yield and ultimate limit state have been investigated and quantified. The conclusions are as follows.

The yield curvature of the T-shaped wall with the flange in tension is mainly affected by the axial load ratio, longitudinal reinforcement ratio, and flange width to web height ratio. When the tensile steel bars determine the yielding of the section at lower axial load levels, the yield curvature increases with the increases in axial load ratio and flange width to web height ratio, but the variation is contrary when compressive concrete determines the yielding of the section at higher axial load levels. The yield curvature consistently increases with increasing longitudinal reinforcement ratio. The main parameters that affect the yield curvature for the flange in compression are the longitudinal reinforcement ratio and web distributed vertical reinforcement ratio; increasing both of them leads to a significant increase in yield curvature.

The ultimate curvature of the T-shaped wall with the flange in tension covers a wide spectrum and exhibits complicated variation trends. The ultimate curvature obviously decreases with the increases in axial load ratio, longitudinal reinforcement ratio, flange width to web height ratio, and web height to thickness ratio, while it increases with increasing transverse reinforcement ratio. The involved parameters do not have significant effect on the ultimate curvature in the flange-in-compression loading direction, among which the effects of the axial load ratio, flange width to web height ratio, and web height to thickness ratio are relatively prominent. The ultimate curvature increases with increasing axial load ratio but decreases with increasing flange width to web height ratio and web height to thickness ratio.

Through the regression analyses of the moment-curvature analyses results of $4941 \mathrm{~T}$-shaped cross-sections, simple expressions to estimate the yield curvature and ultimate curvature of asymmetric flanged walls are developed, and simplified estimates of the ductility capacity, which includes the curvature ductility and displacement ductility, are further deduced. By comparing with the experimental results, we have verified the accuracy of the proposed formulas. Such simple expressions consider the differences in sectional deformation quantities of asymmetric flanged walls under different loading directions and rationally reflect the effects of key parameters, which are valuable for the displacement- based seismic design and performance evaluation of asymmetric flanged reinforced concrete walls.

\section{Data Availability}

The data used to support the findings of this study are available from the corresponding author upon request.

\section{Conflicts of Interest}

The authors declare that there are no conflicts of interest regarding the publication of this paper.

\section{Acknowledgments}

The work was supported by the National Natural Science Foundation of China (Grant nos. 51808435 and 51878540), the China Postdoctoral Science Foundation (Grant no. 2018M643594), the Natural Science Foundation of Shaanxi Province (Grant no. 2019JQ-199), and the Young Talent Fund of University Association for Science and Technology in Shaanxi Province (Grant no. 20190419).

\section{References}

[1] E. Smyrou, T. Sullivan, N. Priestley, and M. Calvi, "Sectional response of T-shaped RC walls," Bulletin of Earthquake Engineering, vol. 11, no. 4, pp. 999-1019, 2013.

[2] M. J. N. Priestley and M. J. Kowalsky, "Aspects of drift and ductility capacity of rectangular cantilever structural walls," Bulletin of the New Zealand National Society for Earthquake Engineering, vol. 31, no. 2, pp. 73-85, 1998.

[3] T. Paulay, "An estimation of displacement limits for ductile systems," Earthquake Engineering \& Structural Dynamics, vol. 31, no. 3, pp. 583-599, 2002.

[4] N. T. Tjen, A. A. Mark, and W. W. John, "Yield displacement estimates for displacement-based seismic design of ductile reinforced concrete structural wall buildings," in Proceedings of the 13th World Conference on Earthquake Engineering, pp. 1-15, WCEE, Vancouver, Canada, August 2004.

[5] H. J. Zhao, X. W. Liang, and C. Song, "Yield displacement calculation method of high-strength concrete shear wall," Journal of Civil, Architectural \& Environmental Engineering, vol. 36, no. 3, pp. 80-85, 2014.

[6] L. M. Massone and J. I. Alfaro, "Displacement and curvature estimation for the design of reinforced concrete slender walls," The Structural Design of Tall and Special Buildings, vol. 25, no. 16, pp. 823-841, 2016.

[7] H. Park, S.-M. Kang, L. Chung, and D.-B. Lee, "Momentcurvature relationship of flexure-dominated walls with partially confined end-zones," Engineering Structures, vol. 29, no. 1, pp. 33-45, 2007.

[8] Y. Zhou, L. Lu, Z. Huang, and D. Li, "Deformation capacity and performance-based seismic design for reinforced concrete coupling beams," Journal of Asian Architecture and Building Engineering, vol. 13, no. 1, pp. 203-208, 2014.

[9] S.-M. Kang and J.-Y. Kim, "Evaluation of deformation capacity including yield deformation in displacement-based design of special RC shear wall," The Structural Design of Tall and Special Buildings, vol. 23, no. 3, pp. 181-209, 2014.

[10] C. Sun, S. Liang, X. Zhu, Y. Song, and D. Wu, "Ductility calculation of prefabricated shear wall with rabbet-unbond 
horizontal connection," Advances in Civil Engineering, vol. 2018, Article ID 5197125, 12 pages, 2018.

[11] G. Monti and F. Petrone, "Yield and ultimate moment and curvature closed-form equations for reinforced concrete sections," ACI Structural Journal, vol. 112, no. 4, pp. 463-474, 2015.

[12] B. Wang, Q.-X. Shi, and W.-Z. Cai, "Seismic behavior of flanged reinforced concrete shear walls under cyclic loading," ACI Structural Journal, vol. 115, no. 5, pp. 1231-1242, 2018.

[13] J. B. Mander, M. J. N. Priestley, and R. Park, "Theoretical stress-strain model for confined concrete," Journal of Structural Engineering, vol. 114, no. 8, pp. 1804-1826, 1988.

[14] J. B. Mander, M. J. N. Priestley, and R. Park, "Observed stressstrain behavior of confined concrete," Journal of Structural Engineering, vol. 114, no. 8, pp. 1827-1849, 1988.

[15] H.-S. Hu, J.-G. Nie, and M. R. Eatherton, "Deformation capacity of concrete-filled steel plate composite shear walls," Journal of Constructional Steel Research, vol. 103, no. 1, pp. 148-158, 2014.

[16] GB50010, Code for Design of Concrete Structures, Architecture Industry Press, Beijing, China, 2010.

[17] M. H. Arslan, "Estimation of curvature and displacement ductility in reinforced concrete buildings," KSCE Journal of Civil Engineering, vol. 16, no. 5, pp. 759-770, 2012.

[18] B. L. Brueggen, Performance of T-shaped reinforced concrete structural walls under multi-directional loading, Ph.D. thesis, University of Minnesota, Minneapolis, MN, USA, 2009.

[19] M. N. Sheikh, H. H. Tsang, and A. Lam, "Estimation of yield curvature for direct displacement-based seismic design of RC columns," in Proceedings of the Australian Earthquake Engineering Conference, pp. 1-11, AEES, Victoria, Australia, January 2008.

[20] J. H. Thomsen and J. W. Wallace, "Displacement-based design of slender reinforced concrete structural walls-experimental verification," Journal of Structural Engineering, vol. 130, no. 4, pp. 618-630, 2004.

[21] T. Paulay and M. J. N. Priestley, Seismic Design of Reinforced Concrete and Masonry Buildings, John Wiley \& Sons, New York, NY, USA, 1992.

[22] Z.-T. Cao, Y.-X. Chen, L.-Y. Wang, and S.-L. Yao, "Study on strength, ductility and hysteretic behavior of reinforced ceramsite concrete members subjected to axial load and flexure," Journal of Building Structures, vol. 9, no. 6, pp. 2-16, 1988.

[23] R. Park and T. Paulay, Reinforced Concrete Structures, John Wiley \& Sons, New York, NY, USA, 1995. 




\section{Enfincering}
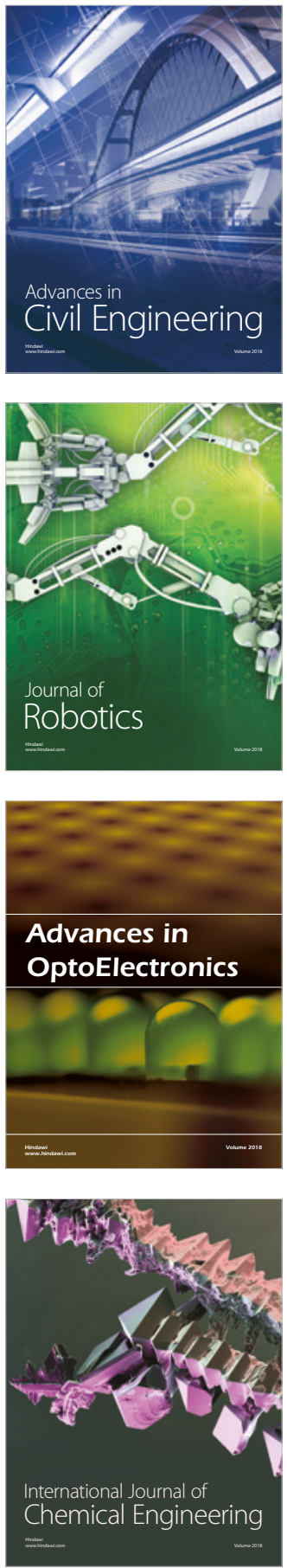

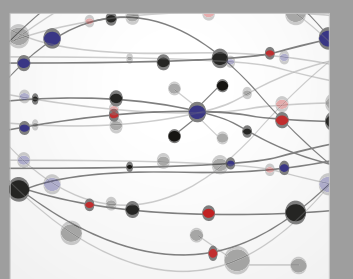

\section{Rotating \\ Machinery}

The Scientific World Journal

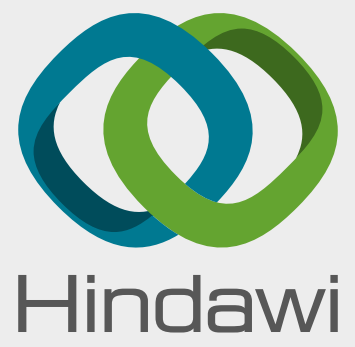

Submit your manuscripts at

www.hindawi.com
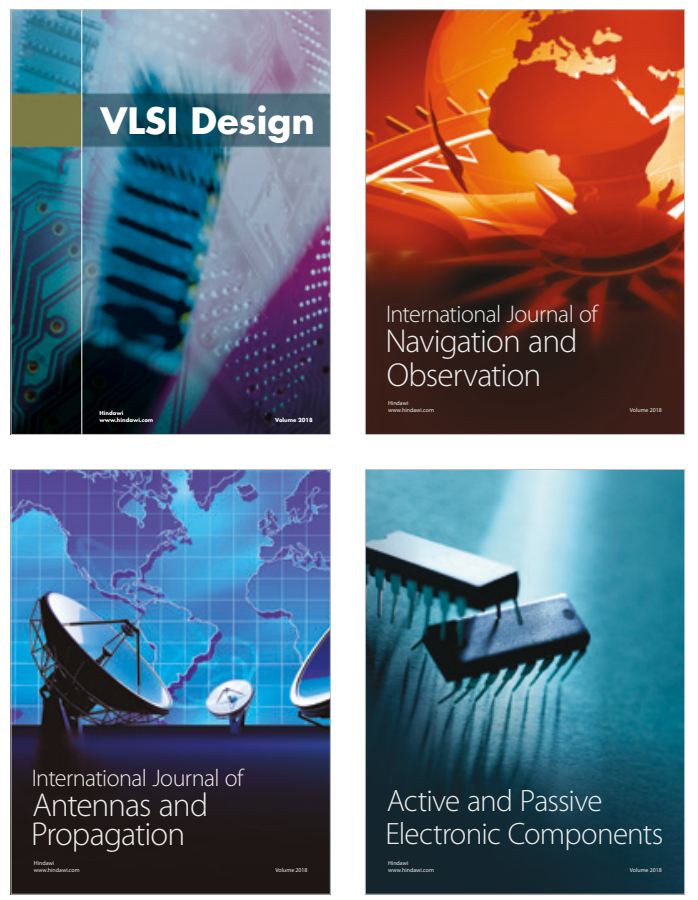
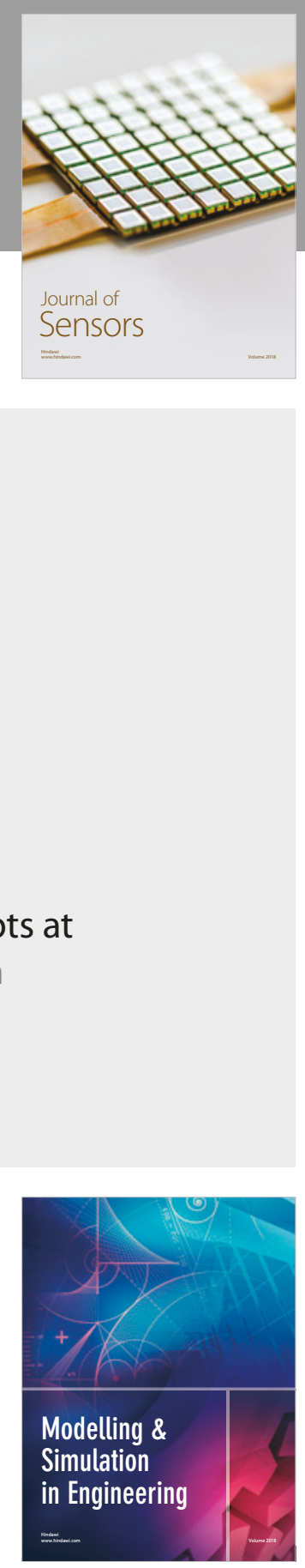

\section{Advances \\ Multimedia}
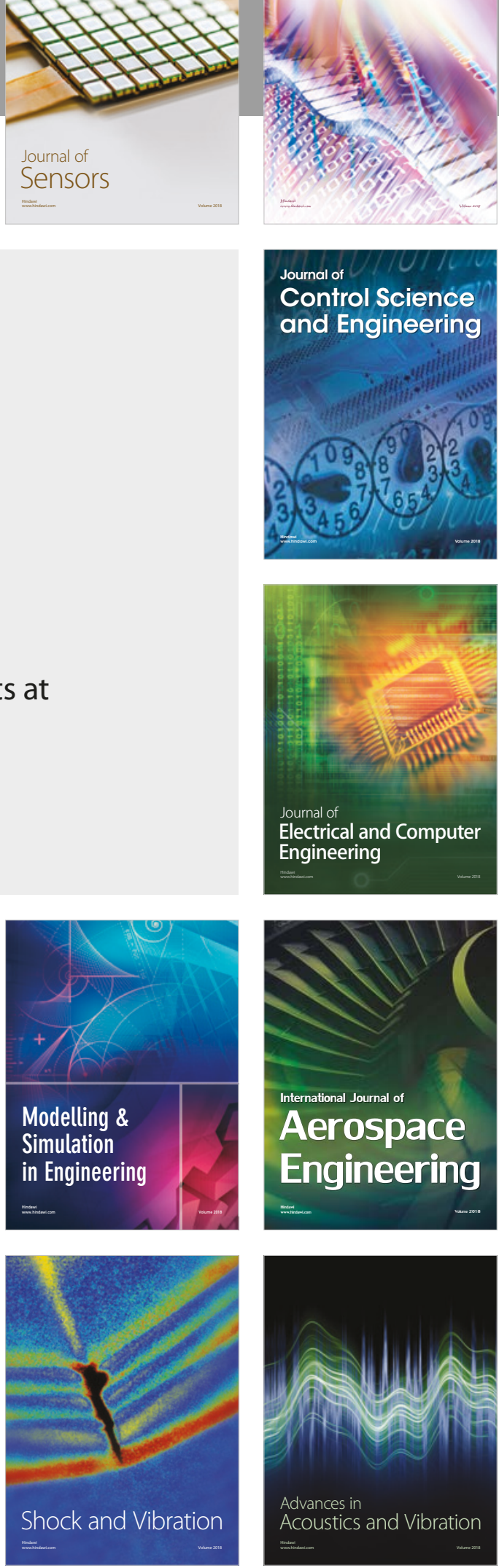